\title{
Selective lung intubation during paediatric thoracic surgeries
}

\author{
Mixa $\mathrm{V}^{1}$, Nedomova $\mathrm{B}^{2}$, Rygl $\mathrm{M}^{3}$ \\ University Hospital Motol, Department of Anaesthesia and Intensive Care Medicine, Prague, Czech Republic. \\ vmxa@volny.cz
}

\begin{abstract}
Selective lung intubation is a necessary prerequisite for the completion of most interventions comprising thoracotomy and thoracoscopy. In paediatric care, our site uses Univent tubes for children up to the age of three years and double-lumen tubes (DLT) for children from 6-8 years of age. In younger children, we usually use regular endotracheal intubation, with the lung being held in the hemithorax position being operated on using a surgical retractor. The article presents the analysis of 860 thoracic surgeries, of which 491 comprised selective intubation (Univent 57 cases, DLT 434 cases). The use of the aforementioned devices is connected with certain complications. Univent tube can be connected with intraoperative dislocation of the obturating balloon (29.8\%) and balloon perforation (5.2\%). DLT insertion may be connected with failure of tube fitting. In 84 cases we had to repeat DLT insertion (20.6\%). In 8 cases we were not able to insert DLT at all (1.8\%).

Standard use of selective intubation methods in paediatric patients from two years of age improved the conditions for surgical interventions (Tab. 2, Fig. 2, Ref. 19). Text in PDF www.elis.sk.

KEY WORDS: paediatric anaesthesia, paediatric thoracic surgery, selective lung intubation, Univent tube, double-lumen tube.
\end{abstract}

\section{Introduction}

Selective lung intubation is one of the necessary prerequisites for successful completion of most interventions comprising thoracotomy and thoracoscopy. In particular, it is necessary in order to prevent the ventilation of the lung being treated due to mechanical ventilation and to limit respiratory movements of the lung that would complicate the surgery. It also prevents the contamination of the other lung with blood and secretions. In adult anaesthesiological care, a double-lumen endobronchial tube or Univent tracheal tube with movable bronchial obturator are usually used for intraoperative selective lung intubation. In paediatric anaesthesia, selective intubation technique is chosen according to patient's age. Particularly in young children this can be a technical problem, which can be approached in various ways. This highly-specialized anaestesiological procedure brings complications, the specifications and enumeration of which are presented below.

Physiological differences in childhood and indications of selective lung intubation

Particularly in newborns and infants there are significant anatomical and physiological differences which have relationship to

${ }^{1}$ University Hospital Motol, Department of Anaesthesia and Intensive Care Medicine, Prague, Czech Republic, ${ }^{2}$ Children's University Hospital Bratislava, Department of Pediatric Anaesthesia and Critical Care Medicine, Bratislava, Slovakia, and ${ }^{3}$ University Hospital Motol, Department of Paediatric Surgery, Prague, Czech Republic

Address for correspondence: V. Mixa, MD, PhD, Department of Anaesthesia and Intensive Care University Hospital Motol, V uvalu 84, CZ-150 06 Praha 5 - Motol, Czech Republic.

Phone: +420.224435481 , Fax: +420.224435420 the indications of selective lung ventilation. The conditions comprise particularly narrow airways with fluffy and fragile mucous membrane, high respiratory frequency and relatively low respiratory volumes. Decrease in lung ventilation due to partial elimination of lung capacity or due to dead space extension quickly leads to hypoxemia. Trachea of infants is 5 to $8 \mathrm{~cm}$ long and measures 5 to $10 \mathrm{~mm}$ in diameter. Both bronchi branch at an angle of approximately $55^{\circ}$ and the angle of the right bronchus is not obtuse as in adults.

Indications of thoracic surgeries differ according to patient's age. The most common indications in newborns and infants are esophageal atresia with tracheoesophageal fistula, cystic adenomatoid pulmonary malformation and pulmonary sequestration. In older children, the diagnoses comprise mediastinal tumours and pulmonary metastases, abscesses, pachypleuritis and other inflammatory complications, and tumours and deformities of the chest wall.

Conduction of anaesthesia and selective lung intubation techniques

Anaesthesia in thoracic surgeries is conducted as sevoflurane supplemented anaesthesia with the use mechanical ventilation, in older children (from the age of about 3 years) it is combined with thoracic epidural analgesia. During the surgery is the patient in thoracotomy position.

The lung to be treated can be separated using several techniques. A method frequently used in young children is endobronchial intubation using a standard tracheal tube inserted in the bronchus of the lung which is not going to be operated on. The advantage is relatively simple completion, the disadvantage is considerable reduction of ventilatory capacity without the possi- 


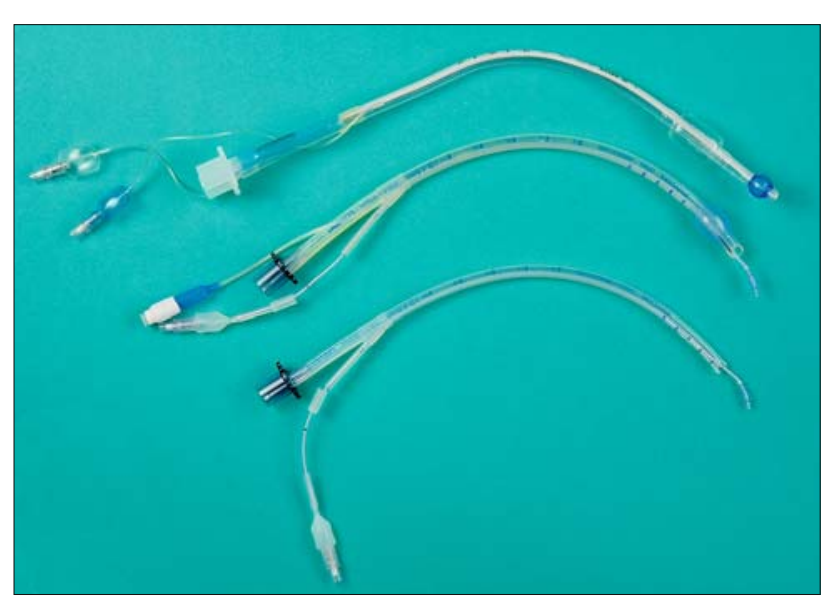

Fig. 1. Tubes used for selective lung intubation in young children. Double-lumen tube No. 26, below Univent No. 4.5 with extended and inflated obturator. At the bottom - the smallest available tube for selective intubation Univent No. 3.5 (see Tab. 1).

bility of intermittent aeration of the lung being operated on $(1,2)$. Endobronchial intubation in a small child can be supplemented by endotracheal intubation using an additional tube which enables to control the ventilation of each lung separately. This technique is not commonly used with respect to high respiratory resistance of these two thin tubes, difficult cleaning of airways and the danger of vocal ligament injury and lower airways injury. Various improvised bronchial obturators are often used, which are either blindly or under fibre optic control inserted in to the lung to be treated and then supplemented with endotracheal intubation. Fogarty thrombectomy catheter or angioplasty catheter are the most commonly reported devices in this context (3). A whole range of bronchial obturators manufactured for this purpose is used for standard completion of this method. Arndt obturator is the most commonly used type $(4,5)$.

The most common devices in anaesthesia for thoracic surgeries in older children are double-lumen tubes, DLT, and Univent tracheal tubes (Fig. 1) with movable bronchial obturator located in a channel in the tube wall (6).

Table 1 comprises the sizes of the devices and corresponding age categories in paediatric patients. It implies the possibility of using Univent tubes in children from the age of three years and double-lumen tubes in children from the age of five years.

\section{Population of patients, results}

Our site performed 860 anaesthesias for thoracotomy and thoracoscopy including surgeries during 2004-2014. The population comprised paediatric patients from newborn to adult age, selective lung intubation was used in 491 cases. Of all devices mentioned above, only Univent tubes (57 cases; 6.6\%) and double-lumen tubes (434 cases; $50.5 \%$ ) were indicated for selective lung intubation during the whole period observed. Table 1 suggests that selective intubation using these devices can be performed in patients from the age of three or five years. Overview of main diagnoses and the number of patients in whom selective lung intubation was performed is summarized in Table 2.
Tab. 1. Comparison of Univent tracheal tube sizes, double-lumen tube ( DLT) sizes and conventional endotracheal tube (ETR ) sizes with respect to patient's age. (I.D. inner diameter of the tube, O.D. outer diameter of the tube).

\begin{tabular}{ccccc}
\hline $\begin{array}{c}\text { Univent } \\
\text { No. } \\
(=\mathrm{I} . \mathrm{D} .[\mathrm{mm}])\end{array}$ & $\begin{array}{c}\text { Univent } \\
\text { O.D. } \\
{[\mathrm{mm}]}\end{array}$ & $\begin{array}{c}\text { DLT } \\
\text { no./O.D. } \\
{[\mathrm{mm}]}\end{array}$ & $\begin{array}{c}\text { Common } \\
\text { ETR No. } \\
(=\mathrm{I} . \mathrm{D} .[\mathrm{mm}]) \\
4.5-5.5\end{array}$ & $\begin{array}{c}\text { Patient's } \\
\text { age } \\
{[\text { years] }} \\
3-5\end{array}$ \\
\hline 4.5 & $7.5-8.0$ & & $5.5-6.0$ & $6-8$ \\
\hline 6.0 & $8.5-9.5$ & $26 / 8.3$ & $6.0-6.5$ & $8-10$ \\
\hline 6.5 & $10.0-11.0$ & $28 / 9.1$ & $6.5-7.0$ & $11-13$ \\
\hline 7.0 & $10.5-11.5$ & $35 / 11.1$ & $7.0-8.0$ & $13-16$ \\
\hline 7.5 & $11.0-12.0$ & $37 / 11.8$ & 8.0 & \\
\hline 8.0 & $12.0-12.5$ & & & \\
\hline 8.5 & $12.5-14.0$ & $39 / 12.4$ & & \\
\hline 9.0 & $13.0-14.0$ & $41 / 13.1$ & \\
\hline
\end{tabular}

Tab. 2. Summary of most common diagnoses which lead to an indication of thoracotomy or thoracoscopy. Numbers of selective intubations using Univent tracheal tubes or double-lumen DLT tubes.

\begin{tabular}{lccc}
\hline Surgery vs diagnosis & in total & Univent & DLT \\
\hline lung resection surgery & 62 & 16 & 35 \\
\hline thoracoscopy & 57 & 14 & 37 \\
\hline pectus excavatum, surgery MIRPE sec. Nuss & 319 & 2 & 317 \\
\hline bronchogenic cyst & 13 & 4 & 1 \\
\hline congenital lobar emphysema & 14 & 1 & 6 \\
\hline pulmonary sequestration & 10 & 0 & 3 \\
\hline congenital adenomatoid pulmonary malformation & 32 & 6 & 2 \\
\hline lung abscess or pulmonary gangrene & 16 & 7 & 3 \\
\hline mediastinal tumour & 43 & 6 & 24 \\
\hline $\begin{array}{l}\text { esophageal atresia with tracheoesophageal } \\
\text { fistula, primary anastomosis }\end{array}$ & 143 & 0 & 0 \\
\hline $\begin{array}{l}\text { esophageal atresia with tracheoesophageal } \\
\text { fistula, repeated surgeries }\end{array}$ & 126 & 0 & 0 \\
\hline other & 25 & 1 & 6 \\
\hline
\end{tabular}

Thoracotomy and thoracoscopy surgeries in young children were performed after standard endotracheal intubation using tubes of appropriate size.

Both methods of selective intubation bring a number of complications. The most frequent complication when using Univent tube is the dislocation of the obturating balloon. We observed this complication in 17 cases, i.e. in $29.8 \%$ of all applications. When detected, this complication can be quickly resolved and the surgery can continue. In three cases (5.2\%), selective lung ventilation was interrupted by perforation of the balloon due to rupture or cutting with a surgical instrument.

DLT insertion may be complicated by failure to fit in the end of the tube to the left bronchus and incorrect position of the lateral opening of the second lumen which is intended for right lung ventilation. In 84 cases we had to repeat DLT insertion (20.6\%). In 8 cases we were not able to insert DLT at all (1.8\%) and the surgery had to be performed with the use of classical endotracheal intubation.

In six cases we encountered a complication during the insertion of a selective ventilation device caused by difficult airway conditions. In three cases, we solved the problem using the Glidescope 
videolaryngoscope $(0.7 \%)$ and in three cases we decided not to perform selective intubation $(0.7 \%)$.

Unlike foreign authors $(7,8)$ who reported tracheal rupture and other injuries, we did not encounter any upper or lower airway injury related to the use of either method.

\section{Discussion}

Although literature often reports various methods of selective intubation in young children with the use of endobronchial intubation (8), potentially with the use of Fogarty catheter or Arndt obturator (9), our experience is that in children at the age of up to two or three years it is possible to successfully perform thoracic surgeries without selective lung ventilation (10). Using moderate pressure of the retractor, the surgeon can push aside the lung in the hemithorax being operated on and the lung movements caused by mechanical ventilation do not interfere with surgeon's activities. The advantage of this technique is that unlike in selective intubation of a separated lung, the compressed lung still has some ventilation capacity, which contributes to the breathing of the child being operated on. If the child needs oxygenation due to a complication, the lung being treated can be aerated using increased inspiratory pressure without any further manipulations. Our site has used this method in all esophageal atresia surgeries and in all other surgeries comprising thoracotomy in paediatric patients up to the age of approximately 2.5 years, i.e. the age which allows for the use of the smallest Univent tracheal tube (size 3.5).

Univent tracheal tube (Fuji System Corporation, Tokyo, Japan) with movable obturator located in a channel in the tube wall $(11,12)$ is a state-of-the-art design product manufactured from high-quality silicone, which is extraordinarily friendly in contact with the fragile mucous membrane of child's lower airways. The use of this device significantly reduced the age limit for selective intubation in children between the second and third year of age. The technique requires experience with the use of fibroscope. The obturator of Univent tube is always inserted under fibrooptic control. The obturator can be inserted in a bronchus of one pulmonary lobe and thus reduces the blocked ventilation capacity (Fig. 2). The most commonly observed complication is intraoperational dislocation of the obturating balloon from the bronchus into trachea and complete closure of trachea. It occurs particularly when using small size tubes (sizes 3.5 and 4.5). Surgical manipulation of the lung can push the obturator from the short child's bronchus into the trachea. This complication can be easily diagnosed. It leads to immediate loss of capnometry curve on the ventilation monitor. The situation quickly adjusts after balloon deflation.

While Univent tubes are used approximately since the middle of the nineties, the double-lumen tracheal tube was introduced in anaesthesiological practice in the fifties. Of all modifications of double-lumen tracheal tubes used in adult anaesthesia, left-side Robertshaw tube proved oneself to be the most suitable for the use in children (13). It does not use a hook that is put on carina tracheae, and as a simple technical solution it allows to reduce the diameters of both lumens and the tube can be adapted for the use in younger children (14). The smallest commonly available size

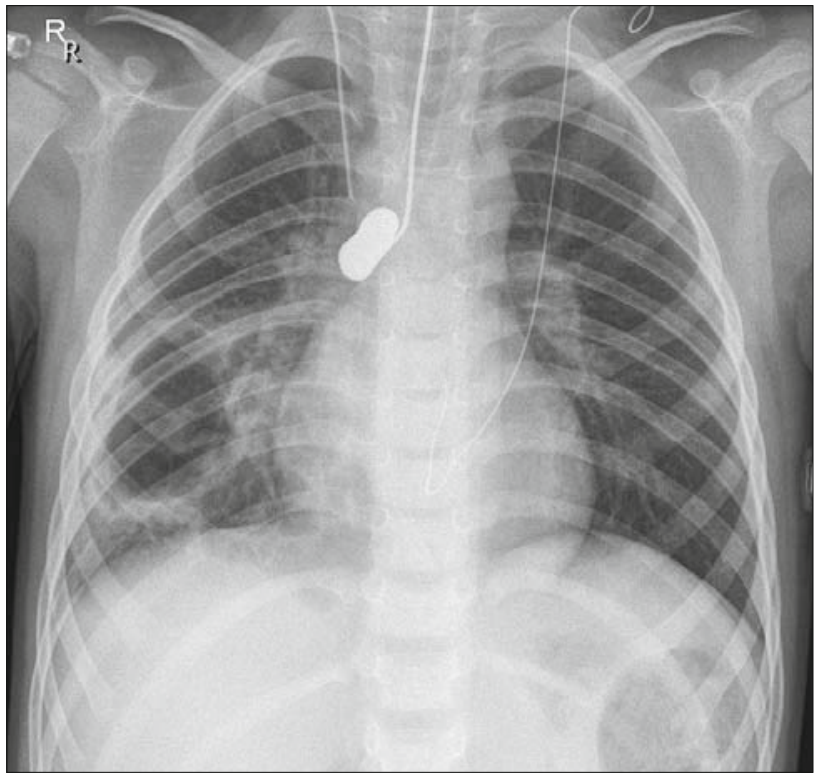

Fig. 2. Chest X-ray, a boy aged 5 years. A big cyst visible in the lower right pulmonary lobe. Univent No. 4.5 tube obturator obturating the main bronchus of the right lung. The obturator is filled with aqueous contrast medium. Central venous catheter inserted in superior vena cava, an epidural catheter visible at Th 9-10 level.

of double-lumen tube is 26 . This size is appropriate for children from the age of approximately six to eight years. The advantage of the left-side design of the tube is that the bronchial lumen is inserted in the left bronchus and fixed by the inflated balloon. The right lumen opens in the trachea opposite to the orifice of the right bronchus. Separation of the right lung is completed through the inflation of the tracheal balloon. This procedure ensures separation of the right upper pulmonary lobe bronchus, which branches perpendicularly at the level of carina tracheae and endobronchial obturation cannot close it. Double-lumen tube insertion is usually controlled using auscultation, the fibroscope is used only later, if problems with tube insertion occur (15).

As for the comparison between both devices, the pros of Univent tubes are more considerate insertion with sufficient time for obturation, minimum manipulation in the reflexogenic zone around carina tracheae and the possibility of selective separation of the respective pulmonary lobes. It can be used even in considerably small children (16). Double-lumen tube allows for quick alternation between right and left lung separation through the closure of the appropriate connector arm, while Univent tube requires relocation of the obturator for other lung under fibrooptic control. It is a noticeable fact that Univent tracheal tube is approximately five times more expensive than the standard double-lumen tube.

\section{Conclusion}

Standard use of Univent tubes and double-lumen tubes of small sizes in paediatric anaesthesia proved itself to be a safe method that allows for radical surgeries and thoracoscopy in children from the age of approximately two to three years. According to our expe- 
$397-400$

rience, selective intubation in smaller children is only exceptionally advantageous. It is beyond any doubt that selective lung intubation in young children is a demanding method which requires a highly-specialized paediatric anaesthesiologist.

\section{References}

1. Jakob A, Bender C, Henschen M, Saueressig U, Uhl M, Krüger M, Franck P, Hentschel R. Selective unilateral lung ventilation in preterm infants with acquired bullousemphysema: a series of nine cases. Pediatr Pulmonol 2013; 48 (1): 9-14.

2. Balegar VK, Barr PA, Mc Cauley JC, Thomas G. Selective bronchial intubation in a preterm infant with congenital cystic adenomatoid malformation and pulmonary air leak syndrome. J Paediatr Child Health 2013; 49 (1): E93-6.

3. Kodivalasa M, Ramachandran G. Selective lung separation with Fogarty catheter guided by an adult fiberoptic bronchoscope in a paediatric patient with situs inversus. Ann Card Anaesth 2009; 12 (1): 83-84.

4. Li PY, Gu HH, Liang WM. Sequential one-lung ventilation using one Arndt endobronchial blocker in a pediatric patient undergoing bilateral, video-assisted thoracoscopic surgery (VATS). J Clin Anesth 2009; 21 (6): 464.

5. Hamer G. Anesthesia for Thoracic Surgery In: Davis PJ, Cladis FP, Motojama EK (Eds). Anesthesia for Infant and Children. Philadelphia: Elsevier Mosby, 2011: 767-791.

6. Gašparec P, Zamborská K. Thorakoskopické výkony In: Gašparec P. Princípy detskej anestézie. Martin: Osveta, 2010: 454-465.

7. Hasan A, Low GW, Ganado AL et al. Trachea rupture with disposable PVC double lumen tube. J Cardiothorac Vasc Anesth 1992; 6: 208-211.

8. Fitzmaurice BG, Brodsky JB. Airway rupture from double lumen tubus. J Cardiothorac Vasc Anesth 1999; 13: 322-329.

9. Ho AM, Karmakar MK, Critchley LA, Ng SK, Wat CY. Placing the tip of the endotracheal tube at the carina and passing the endobronchial blocker through the Murphy eye may reduce the risk of blocker retrograde dislodgement during one-lung anaesthesia in small children. Br J Anaesth 2008; 101 (5): 690-693.

10. Sutton CJ, Naguib A, Puri S, Sprenker CJ, Camporesi EM. Onelung ventilation in infants and small children: blood gas values. J Anesth 2012; 26 (5): 670-674.

11. Kayama H. Krishna PR. New endotracheal tube (Univent Tube) for selective blocade of one lung. Anestesiology 1985; 63: 342-343.

12. Hammer GB, Brodsky JB, Redpath $\mathbf{J}$ et al. The Univent tube for single lung ventilation in children. Paed Anaesth 1998; 8: 55-57.

13. Larsen R. Anestézie při ventilaci jedné plíce In: Larsen R. Anestézie. Praha: Grada Publishing, 1998: 673-679.

14. Tejman-Yarden S, Lederman D, Eilig I, Zlotnik A, Weksler N, Cohen A, Gurman GM. Acoustic monitoring of double-lumen ventilated lungs for the detection of selective unilateral lung ventilation. Anesth Analg 2006; 103 (6): 1489-1493.

15. Byon HJ, Lee JW, Kim JK, Kim JT, Kim YT, Kim HS, Lee SC, Kim CS. Anesthetic management of video-assisted thoracoscopic surgery (VATS) in pediatric patients: the issue of safety in infant and younger children. Korean J Anesthesiol 2010; 59 (2): 99-103.

16. Chengod S, Chandrasekharan AP, Manoj P. Selective left bronchial intubation and left-lung isolation in infants and toddlers: analysis of a new technique. J Cardiothorac Vasc Anesth 2005; 19 (5): 636-641.

17. One-lung ventilation in children using the single-lumen tracheal tube. Middle East J Anaesthesiol 2012; 21 (4): 455-456.

18. Fuchs J, Kirschner HJ, Warmann SW, Schelinger K, Baden W, Szavay P. Thoracoscopic anatomical lung resection in children. Zbl Chir 2007; 132 (3): 247-250.

19. Tercan E, Sungun MB, Boyaci A, Kücükaydin M. One lung ventilation of pretermnewborn during esophageal atresia and tracheoesophageal fistula repair. Acta Anaesthesiol Scand 2002; 46 (3): 332-333.

Received November 12, 2015. Accepted December 2, 2015. 